\title{
Screening and Fermentation Characteristics of PHA Bacteria in Activated Sludge*
}

\author{
Yang Fang, Zhu Rui \\ Hebei Electric Power Design \& Research Institute, Hebei, China \\ Email: zhurui423@163.com, bdsunjinxu@163.com
}

Received 2013

\begin{abstract}
Using sludge at the bottom of Hengshui Lake as samples, and screened out the SJ-9 strain with PHA synthesis capability by enrichment, purification, Nile blue staining, far-infrared spectroscopy and gas qualitative and quantitative analysis. The infrared scanning of SJ-9 bacteria product showed that this product was middle chain PHA. Optimization of SJ-9 fermentation conditions obtained the optimal conditions with optimal carbon source of sodium butyrate, optimal $\mathrm{C} / \mathrm{N}$ of 35, optimal fermentation time of $120 \mathrm{~h}$, and optimal initial pH for culture substrate of 7.0.10 L fermenter amplification culture under these conditions showed consistent results with flask culture, and the bacteria and PHA had the highest yields at $120 \mathrm{~h}$, with the maximal yields of 6.81 and $2.36 \mathrm{~g} / \mathrm{L}$, respectively.
\end{abstract}

Keywords: PHA; Screening; Infrared Spectroscopy

\section{Introduction}

Facing the constantly increasing threat of oil resource depletion and environmental pollution in the past two decades, PHA (poly-hydroxy fatty acid esters) has attracted more and more attention because it can be completely biodegraded and can be used to synthesize renewable resources [1]. It is considered to be environmentally friendly "biodegradable plastic". With more and more in-depth understanding of PHA, its application has been developed. For example, it can be used to make thermal-sensitive adhesive, pressure-sensitive adhesive and hydrosol, can be pulled into a fiber, and can be used as medical implant materials on the basis of its biodegradable and biocompatible characteristics.

Biosynthesis of PHA is a complex process catalyzed by a variety of enzymes and controlled by different metabolic pathways. Thus, biological synthesis of PHA has low yield and high cost. How to improve PHA yield and reduce PHA production cost are still key for its development and application. This study aimed to use activated sludge screening to obtain strains with high PHA yield and study the fermentation characteristics of PHAproducing strains to increase PHA yield, reduce PHA production cost, and to further expand the development and application of PHA and benefit mankind.

*Fund Projects: Science\& Technology of Hebei (Serial number: 10215522).

\section{Materials and Methods}

\subsection{Materials}

\subsubsection{Screening Sample}

1) Experimental activated sludge was from the bottom of Hengshui Lake.

2) PHA standard was purchased from National Reference Materials website.

\subsubsection{Medium}

1) Enrichment medium (g/100 mL)

Peptone 1, Beef extract 0.5 , and $\mathrm{NaCl} 1.5$.

2) Isolation and enrichment medium $(\mathrm{g} / 100 \mathrm{~mL})$

Beef extract 0.3, Peptone 1, NaCl 1.5, Agar 1.5, and Nile blue dye $0.5 \mu \mathrm{g} / 100 \mathrm{~mL}$, $\mathrm{pH} 7$.

3) Liquid medium (g/L)

Glucose 30.0, Yeast extract 6.0, $\left(\mathrm{NH}_{4}\right)_{2} \mathrm{SO}_{4} 1.0$, Automatic $\mathrm{pH}$.

\subsubsection{Experimental Methods}

1) Enrichment and Purification of Target Bacteria

5 g sample (From sludge at Hengshui Lake bottom) was added to $500 \mathrm{~mL}$ flask containing $150 \mathrm{~mL}$ enrichment medium, and cultured in shaking incubator at $30^{\circ} \mathrm{C}$ for 24 h. $0.1 \mathrm{~mL}$ enrichment fluid was diluted by with sterile water to $10^{-1}, 10^{-2}, 10^{-3}, 10^{-4}$, and $10^{-5}$, coated respectively, and incubated at $30^{\circ} \mathrm{C}$ for $24 \mathrm{~h}$. Single colonies were picked for purification culture in beef extract peptone slant medium at $30^{\circ} \mathrm{C}$ for $24 \mathrm{~h}$. The growth of 
bacteria was examined under microscope to obtain single colonies, which were processed by $0.5 \%$ Nile blue dye staining, and $10 \mathrm{~min}$ later, washed with water to remove dye and dried with filter paper.

2) Screening of PHA-Producing Strains

Purified single colony was transferred to plate with PHA-producing medium, cultured at $30^{\circ} \mathrm{C}$ for $24 \mathrm{~h}$, stained with $0.5 \%$ Nile blue dye, then 10 min later, washed with water to remove dye, dried with filter paper, and observed under UV light. The target bacteria contains fluorescence.

3) Individual strain morphology, Gram staining, etc. were as described by reference [2]

\section{4) PHA extraction [3]}

Screened PHA-synthesis strain was inoculated into liquid medium and cultured for $48 \mathrm{~h}$. The culture medium was centrifuged at $3500 \mathrm{r} / \mathrm{min}$ for $30 \mathrm{~min}$, and then the centrifuged sediment was frozen-dried for $10 \mathrm{~h}$, heated in boiling water bath for 30 min, and repeated freezing-thawing for three times. The broken sediments after freezing-thawing were placed in a mortar, grinded in $4^{\circ} \mathrm{C}$ cold acetone for $30 \mathrm{~min}$, and filtered. The residues were extracted with $50^{\circ} \mathrm{C}$ hot chloroform for three times, each time $8 \mathrm{~h}$. After filtered, the extracted liquid was combined and condensed to $5 \mathrm{~mL}$ by rotary evaporation. Then $200 \mathrm{~mL}$ of $-20^{\circ} \mathrm{C}$ methanol was added, and crude PHA was obtained after standing overnight. The products were dissolved in chloroform and precipitated by methanol for two more times, and the sediments were dried at $50^{\circ} \mathrm{C}$ to obtain refined PHA products.

5) PHA analysis method [4]

Gas chromatography analysis (Gas chromatograph was Agilent GC7890) was performed by internal standard method. $5 \mathrm{mg}$ purified PHA samples and standards were weighed accurately, and $1 \mathrm{ml}$ chloroform and $1 \mathrm{ml}$ acidified methanol (containing 3\% sulfuric acid $(v / v)$ and $200 \mathrm{mg} / \mathrm{L}$ internal standard benzoic acid) were added. The test tube was tightly capped to close itself. The sample was methyl esterified at boiling water bath for $4 \mathrm{~h}$, cooled to room temperature, supplemented with $1 \mathrm{ml}$ distilled water, shaken completely, and centrifuged at 3000 $\mathrm{r} / \mathrm{min}$ for $5 \mathrm{~min}$. The lower chloroform layer was analyzed by gas chromatography. GC conditions: Agilent DB-1 GC column with the column length of $2 \mathrm{~m}$, carrier $\mathrm{N}_{2}$ with a $40 \mathrm{ml} / \mathrm{min}$ flow, $200^{\circ} \mathrm{C}$ injector temperature, $250^{\circ} \mathrm{C}$ detector temperature, column temperature for 2 min then increased to $195^{\circ} \mathrm{C}$ by $20^{\circ} \mathrm{C} / \mathrm{min}$ and keep $3 \mathrm{~min}$, and FID detector for analysis. The content was represented by the peak area ratio of sample and standard.

\section{Results and Discussion}

1) Screening of PHA producing strains

Under UV lamp, fluorescent colonies were picked from Nile blue plate and stained with Sudan black, five strains were screened with PHA synthesis capability. The 5 strains from primary screening were fermented in flasks, and PHA content of each strain was determined by gas chromatography. The results were shown in Table 1.

As shown in Table 1, the 5 screened strains were all Bacilli, and were Gram positive after Gram staining. Gas chromatography analysis for PHA content showed that strain SJ-9 produced the highest level of PHA, which was $180 \%$ higher than that in SJ-11 strain with the lowest yield. Therefore, SJ-9 strain was selected for the following research object.

2) PHA far-infrared structure of PHA produced by SJ-9 strain

After fermentation and centrifugation of fermentation broth, the obtained PHA from wet cells extraction was dissolved in chloroform to determine its structure by IR (Infrared spectrometer (AVTAR36O) was from Thermo Fisher Nicolet). The results were shown in Figure 1.

As shown in Figure 1, the PHA produced by screened SJ-9 strains had a strong absorption peak at $1730-1740$ $\mathrm{cm}^{-1}$, which is the absorption peak of PHA characteristic group $\mathrm{C}=\mathrm{O}$, indicating that product is PHA. In addition

Table 1. Accumulated PHA and morphological features of different strains.

\begin{tabular}{cccc}
\hline $\begin{array}{c}\text { Strain } \\
\text { (serial number) }\end{array}$ & Characteristic & $\begin{array}{c}\text { Reaction } \\
\text { of Gram }\end{array}$ & $\begin{array}{c}\text { The content } \\
\text { of PHA(g/L) }\end{array}$ \\
\hline SJ-2 & rod & $\mathrm{G}^{+}$ & 1.25 \\
SJ-5 & rod & $\mathrm{G}^{+}$ & 1.02 \\
SJ-9 & rod & $\mathrm{G}^{+}$ & 1.85 \\
SJ-11 & rod & $\mathrm{G}^{+}$ & 0.66 \\
SJ-20 & rod & $\mathrm{G}^{+}$ & 1.12 \\
\hline
\end{tabular}

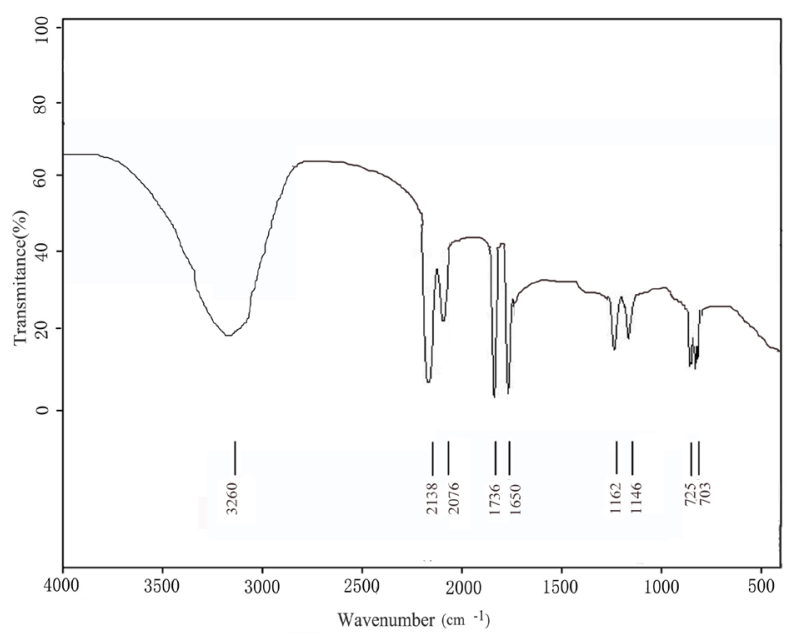

Figure 1. Infrared spectroscopy of strain SJ-9. 
to a strong absorption peak at $1736 \mathrm{~cm}^{-1}$, the strain also had a strong absorption band at $1160 \mathrm{~cm}^{-1}$ and a weak absorption band at $720 \mathrm{~cm}^{-1}$, indicating that the PHA produced by SJ-9 strain is middle chain [2].

3) Static experiment of factors that impact PHA-producing strain SJ-9

\subsection{The Impacts of Different Carbon Sources on Bacteria Growth and PHA Production}

In order to examine the impacts of carbon source on SJ-9 bacterial growth and PHA synthesis, we designed a carbon source single factor impact using $\left(\mathrm{NH}_{4}\right)_{2} \mathrm{SO}_{4}$ concentration of $1 \mathrm{~g} / \mathrm{L}$, fermentation time of $120 \mathrm{~h}$, and automatic $\mathrm{pH}$ value. The results were shown in Figure 2.

As shown in Figure 2, SJ-9 bacteria grow well when using sodium acetate, sodium propionate and sodium butyrate as carbon source. The dry weight of bacteria was the highest when using butyric acid as carbon source, reaching $5.96 \mathrm{gL}$, and PHA content was $2.21 \mathrm{~g} / \mathrm{L}$. These indicated that different carbon sources had certain influence on bacteria growth and PHA yield, and the impact of carbon source on bacteria growth and PHA yield was sodium butyrate $>$ propionate $>$ acetate.

\subsection{The Impacts of Different C/N Ratios on Bacteria Growth and PHA Production}

PHA is a type of thermoplastic polyester formed by prokaryotic microbes under carbon and nitrogen imbalance as the storage of carbon and energy [5], so the $\mathrm{C} / \mathrm{N}$ of fermentation substrate has a significant impact on the synthesis of bacterial PHA. To determine the PHA synthesis of obtained strain under substrates with different nutritional ratio, we designed different $\mathrm{C} / \mathrm{N}$, with initial

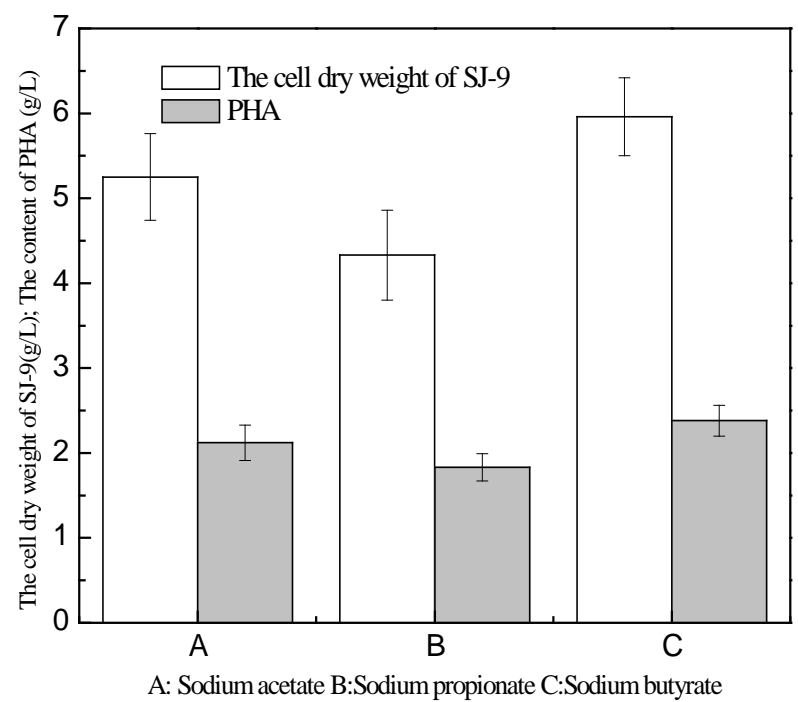

Figure 2. The carbon source effect for the cell weight of SJ-9 and PHA. fermentation time of $120 \mathrm{~h}$, carbon source of sodium butyrate, nitrogen source of $1 \mathrm{~g} / \mathrm{L}\left(\mathrm{NH}_{4}\right)_{2} \mathrm{SO}_{4}$, incubation time of $120 \mathrm{~h}$, and automatic $\mathrm{pH}$ to identify the best $\mathrm{C} / \mathrm{N}$ in substrate. The results were shown in Figure 3.

As shown in Figure 3, the SJ-9 bacteria and PHA yield augmented as $\mathrm{C} / \mathrm{N}$ in media substrate increased. When the substrate medium had a $\mathrm{C} / \mathrm{N}$ of 35 , the $\mathrm{SJ}-9$ bacteria and PHA yield were highest, with the maximal bacteria yield of $6.31 \mathrm{~g} / \mathrm{L}$ and maximal PHA yield of $2.36 \mathrm{~g} / \mathrm{L}$. Then bacteria yield and PHA yield decreased as $\mathrm{C} / \mathrm{N}$ increased. The reason may be that the PHA synthesis rates were varied at different $\mathrm{C} / \mathrm{N}$. When $\mathrm{C} / \mathrm{N}$ was above 35 , bacteria growth required longer time to reach stabile phase. When the bacteria growth reached stabile phase, substrate concentration became limiting factor compared to the large amount of bacteria, and the microbes began to synthesize a large number of PHA. For the above reasons, we can consider extending the fermentation time at high $\mathrm{C} / \mathrm{N}$. The substrate $\mathrm{C} / \mathrm{N}$ meeting the requirement of PHA accumulation may benefit the bacterial synthesis of PHA at certain extent.

\subsection{The Impacts of Fermentation Time on Bacteria Growth and PHA Production}

PHA is a product of bacterial metabolism [6]. Large amount of PHA accumulation occurs after bacterial growth reached the stable phase. Different microbes require different time to reach stable phase, and had different PHA accumulation rates. Therefore, we investigated the PHA synthesis at $\mathrm{C} / \mathrm{N}$ of 35 and extended fermentation time. Samples were collected every $12 \mathrm{~h}$, and the results were shown in Figure 4.

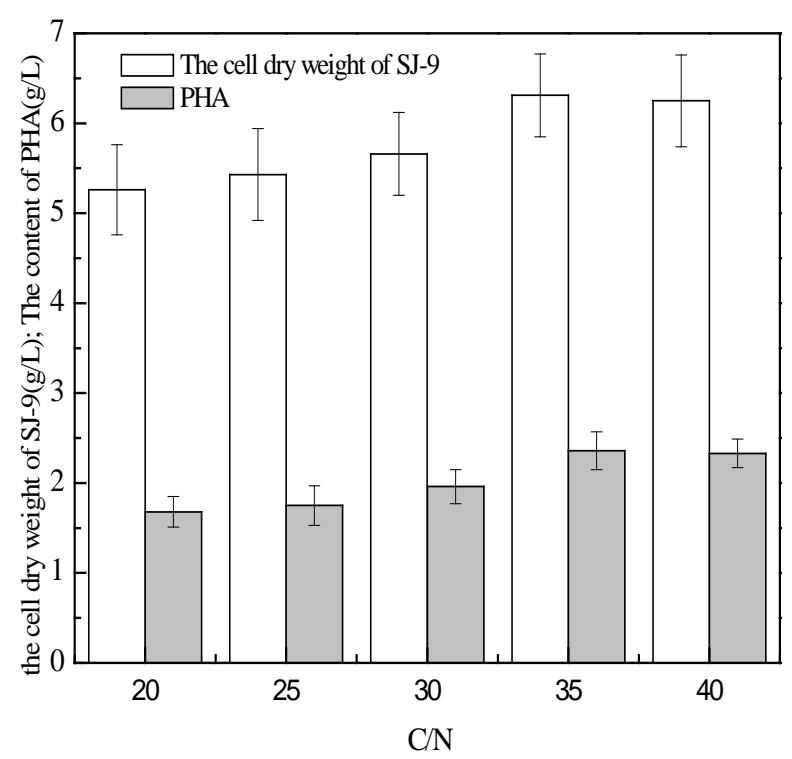

Figure 3. The $\mathrm{C} / \mathrm{N}$ effect for the cell weight of $\mathrm{SJ}-9$ and PHA. 


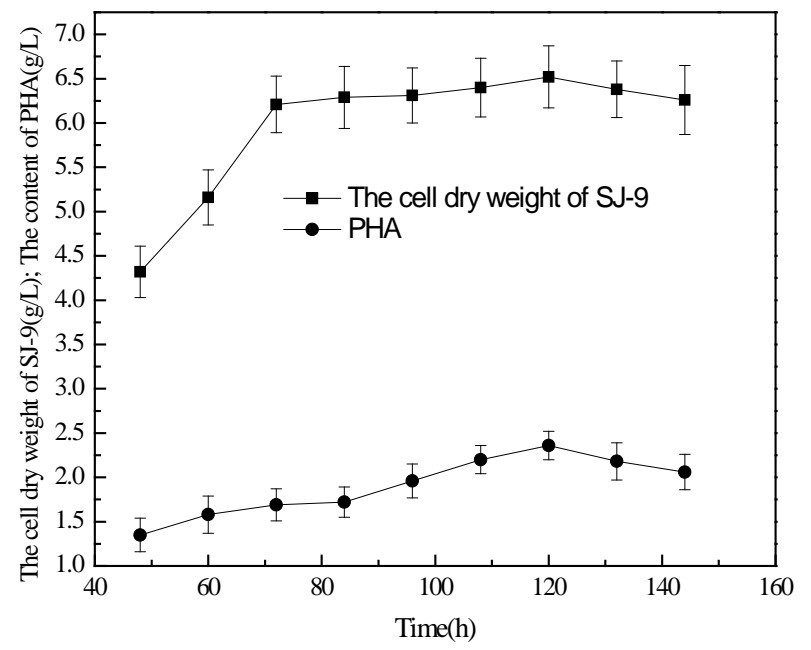

Figure 4. The fermentation time effect for the cell weight of SJ-9 and PHA.

As shown in Figure 4, bacterial growth and PHA accumulation showed positive correlation at certain level, i.e., synergistic growth. At the beginning, bacterial growth was slow and PHA synthesis was rare; at the logarithmic growth phase, bacteria and PHA yields increased rapidly; at $120 \mathrm{~h}$, the bacteria and PHA yields were maximal, and the highest yield of bacteria and PHA were $6.52 \mathrm{~g} / \mathrm{L}$ and $2.36 \mathrm{~g} / \mathrm{L}$, respectively. Therefore, 120 $\mathrm{h}$ is the appropriate fermentation time.

\subsection{The Impacts of pH on Bacteria Growth and PHA Production}

It is known from relevant literature that the initial $\mathrm{pH}$ of culture substrate also influences the PHA accumulation in bacteria. Therefore, we investigated the impacts of initial $\mathrm{pH}$ of fermentation medium on SJ-9 bacterial growth and PHA production under optimal carbon source, $\mathrm{C} / \mathrm{N}$ of 35 , and fermentation time of $120 \mathrm{~h}$. The results were shown in Figure 5.

As shown in Figure 5, the initial pH of culture substrate had great impact on SJ-9 bacterial growth and PHA synthesis. when the $\mathrm{pH}$ is lower than 7.0, SJ-9 bacterial growth and PHA production augmented with increasing $\mathrm{pH}$; at $\mathrm{pH}$ value of 7, the bacteria and PHA yields were highest, with the maximal yields of 6.68 and $2.46 \mathrm{~g} / \mathrm{L}$, respectively; however, the bacteria and PHA yields decreased with increasing $\mathrm{pH}$, indicated that neutral $\mathrm{pH}$ was appropriate for SJ-9 bacterial growth and PHA production.

\subsection{Dynamics of PHA Accumulation in SJ-9 Bacteria}

We used dynamic experiment to perform amplification studies on the SJ-9 bacterial growth and PHA production

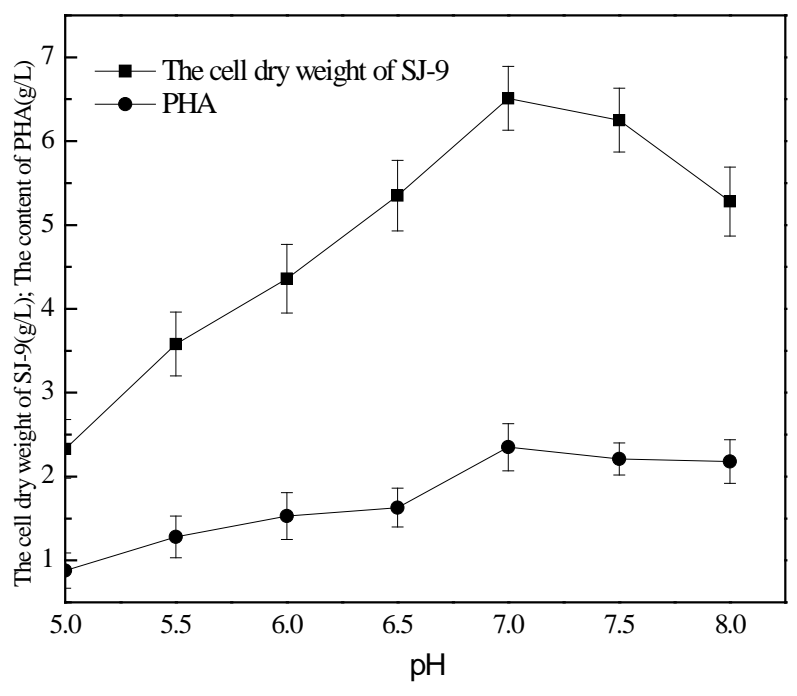

Figure 5. pH effect for the cell weight of SJ-9 and PHA.

during fermentation in $10 \mathrm{~L}$ fermenter $(10 \mathrm{~L}$ fermenter was from Biostat Bplus), with the carbon source of sodium butyrate, nitrogen source of $1 \mathrm{~g} / \mathrm{L}\left(\mathrm{NH}_{4}\right)_{2} \mathrm{SO}_{4}, \mathrm{C} / \mathrm{N}$ of 35 , fermentation time of $120 \mathrm{~h}$, and $\mathrm{pH}$ value of 7 . The results were shown in Figure 6

As shown in Figure 6, during the entire fermentation process, the $\mathrm{pH}$ showed a steady upward trend. At 0 $120 \mathrm{~h}$, a lot of carbon was consumed and nitrogen also decreased; at this stage, bacterial dry weight grew fast, bacteria was in logarithmic growth phase, SJ-9 bacteria and PHA yields continue to rise, reached the maximal level simultaneously at $120 \mathrm{~h}$, with the highest yields of 6.81 and $2.36 \mathrm{~g} / \mathrm{L}$, respectively. Then as the fermentation time increased, bacteria and PHA yields both declined, which was consistent with the previous flask experiments. In the fermenter, bacteria growth and PHA yield were stable, which are of great significance for the future application and PHA production.

\section{Conclusions}

1) Using Hengshui lake bottom sludge as samples, we isolated and screened 5 strains with PHA synthesis capability. After yield comparison, the SJ-9 bacterium was finally used as research object. The infrared spectra scanning of PHA showed that the PHA produced by SJ-9 bacteria had a strong absorption peak at $1730-1740$ $\mathrm{cm}^{-1}$, which is caused by the characteristic group $\mathrm{C}=\mathrm{O}$ of PHA, indicated that product is PHA. In addition to a strong absorption peak at $1736 \mathrm{~cm}^{-1}$, the strain had another strong absorption band at $1160 \mathrm{~cm}^{-1}$ and a weak absorption band at $720 \mathrm{~cm}^{-1}$, indicating that the PHA produced by SJ-9 strain is middle chain.

2) The SJ-9 fermentation conditions were investigated and obtained, the optimal conditions for SJ-9 fermentation culture are: suitable carbon source is sodium 


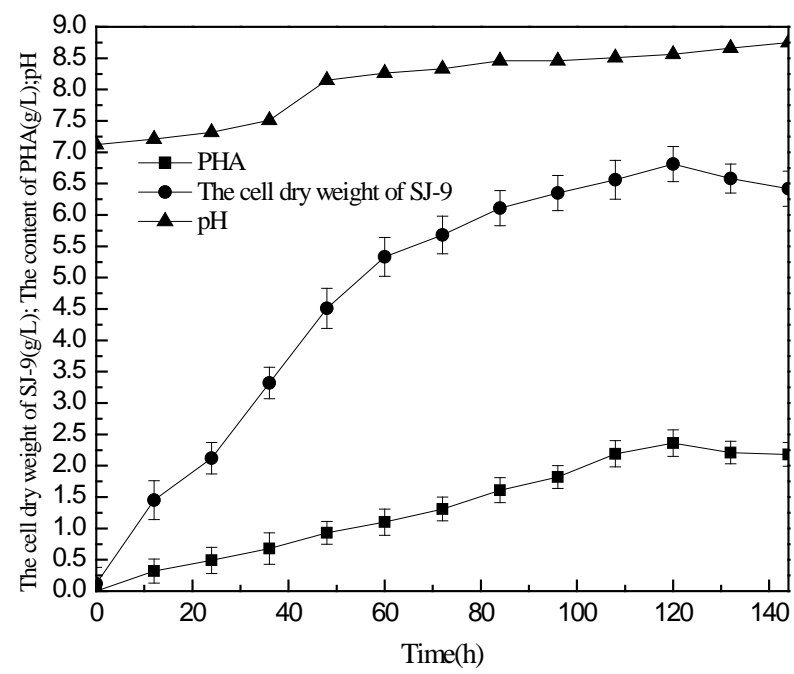

Figure 6. The amplifying research of $10 \mathrm{~L}$ fermentor for SJ-9.

butyrate, suitable $\mathrm{C} / \mathrm{N}$ is 35 , suitable fermentation time is $120 \mathrm{~h}$, and suitable initial $\mathrm{pH}$ of culture substrate is 7.0.

3) Amplification culture of SJ-9 was performed in 10 $\mathrm{L}$ fermenter, and the results were the same as flask culture. At $120 \mathrm{~h}$, the bacteria and PHA yields were maximal simultaneously, with the highest yield of 6.81 and 2.36 $\mathrm{g} / \mathrm{L}$, respectively. During the fermenter culture process, the bacteria growth and PHA yield was stable, which is of great significance for the future applications and PHA production.

\section{References}

[1] C. Suchada, "Current Trends in Biodegradable Polyhydroxyalkanoates," Journal of Bioscience and Bioengineering, Vol. 110, 2010, pp. 621-632.

http://dx.doi.org/10.1016/j.jbiosc.2010.07.014

[2] B. Hazer and C. Steinb, "Increased Diversification of Polyhydroxyalkanoates by modiFication Reactions for Industrial and Medical Applications," Applied Microbiology and Biotechnology, Vol. 74, 2005, pp. 1-12. http://dx.doi.org/10.1007/s00253-006-0732-8

[3] R. W. Lenz and H. Merchessaultr, "Bacterial Polyesters: Biosynthesis Biodegradable Plastics and Biotechnology," Biomacromolecules, Vol. 6, 2005, p. 1. http://dx.doi.org/10.1021/bm049700c

[4] J. M. Cavalheiro and M. C. Almeida, "Poly (3-Hydroxybutyrate) Production by Cupriavidus Necator Using Waste Glycerol,” Process Biochemistry, Vol. 44, 2009, pp. 509-515. http://dx.doi.org/10.1016/j.procbio.2009.01.008

[5] J. H. Song, C. O. Jeon and H. Choim, "Polyhydroxyalkanoate (PHA) Production Using Waste Vegetable Oil by Pseudomonas sp. Strain $\mathrm{Dr}_{2}$," Journal of Microbiology and Biotechnology, Vol. 18, 2008, pp. 1408 -1415.

[6] A. J. Verlinden and D. J. Hill, "Bacterial Synthesis of Biodegradable Polyhydroxyalkanoates,” Journal of Applied Microbiology, Vol. 102, 2007, pp. 1227-1229. http://dx.doi.org/10.1111/j.1365-2672.2007.03335.x 